\title{
Knowledge and attitude toward interdisci
team working among obstetricians and gynecologists in teaching hospitals in South East Nigeria
}

\author{
This article was published in the following Dove Press journal: \\ Journal of Multidisciplinary Healthcare \\ 26 May 2015 \\ Number of times this article has been viewed
}

\author{
Chukwuemeka Anthony \\ lyoke' \\ Lucky Osaheni Lawani² \\ George Onyemaechi Ugwu' \\ Leonard Ogbonna Ajah ${ }^{2}$ \\ Euzebus Chinonye Ezugwu' \\ Paul Onah' \\ Chidinma Ifechi Onwuka' \\ 'Department of Obstetrics and \\ Gynaecology, University of Nigeria \\ Teaching Hospital, Ituku-Ozalla, Enugu, \\ Nigeria; ${ }^{2}$ Department of Obstetrics \\ and Gynaecology, Federal Teaching \\ Hospital, Abakaliki, Nigeria
}

Correspondence: Chukwuemeka Anthony lyoke

Department of Obstetrics and Gynaecology, University of Nigeria

Teaching Hospital, PO Box 4994,

Enugu Headquarters, Enugu 40000I,

Nigeria

Tel +234808583 II 67

Email caiyoke@yahoo.co.uk
Background: Interdisciplinary team working could facilitate the efficient provision and coordination of increasingly diverse health services, thereby improving the quality of patient care. The purpose of this study was to describe knowledge of interdisciplinary team working among obstetricians and gynecologists in two teaching hospitals in South East Nigeria and to determine their attitude toward an interdisciplinary collaborative approach to patient care in these institutions.

Methods: This was a questionnaire-based cross-sectional study. Data analysis involved descriptive statistics and was carried out using Statistical Package for the Social Sciences software version 17.0 for Windows.

Results: In total, 116 doctors participated in the study. The mean age of the respondents was $31.9 \pm 7.0$ (range $22-51$ ) years. Approximately $74 \%$ of respondents were aware of the concept of interdisciplinary team working. Approximately $15 \%$ of respondents who were aware of the concept of interdisciplinary team working had very good knowledge of it; $52 \%$ had good knowledge and $33 \%$ had poor knowledge. Twenty-nine percent of knowledgeable respondents reported ever receiving formal teaching/training on interdisciplinary team working in the course of their professional development. About $78 \%$ of those aware of team working believed that interdisciplinary teams would be useful in obstetrics and gynecology practice in Nigeria, with $89 \%$ stating that it would be very useful. Approximately $77 \%$ of those aware of team working would support establishment and implementation of interdisciplinary teams at their centers.

Conclusion: There was a high degree of knowledge of the concept and a positive attitude toward interdisciplinary team working among obstetricians and gynecologists in the study centers. This suggests that the attitude of physicians may not be an impediment to implementation of a collaborative interdisciplinary approach to clinical care in the study centers.

Keywords: team working, interdisciplinary, Nigeria, obstetrics, gynecology

\section{Introduction}

Team working in health care involves interaction among health professionals who work interdependently to provide a given type of care. ${ }^{1-3}$ Multiprofessional team working has been classified into three major types, each of which has its own characteristics related to the amount and type of collaboration among team members. ${ }^{4}$ These include multidisciplinary, interdisciplinary, and transdisciplinary team working. ${ }^{4-7}$

The need for team working and collaboration in health care delivery for the purpose of improving patient outcomes has been a major area of research in the last two decades. ${ }^{8-10}$ Team working has been shown to be desirable for achieving quality 
outcomes in health services through facilitation of information flow and coordination and provision of health care within the increasing diversity of disciplines in health care. ${ }^{11}$ Studies have shown that team work is an important factor in prevention of adverse patient events in health care. ${ }^{12}$

In Nigeria, anecdotal evidence shows that clinical services are often organized along strict professional lines and teams are formed by and within individual professions independent of one another. Consultant-led obstetrics and gynecology teams (units), for instance, are made up of doctors only and deliver services along strict professional lines. Nursing care is often organized according to wards and clinics, and complements the medical care in those wards and clinics. Similarly, pharmacy and laboratory services function almost completely independently. Collaboration among these groups occurs only to the extent that each group carries out its functions to permit patient care to proceed in a coordinated fashion. A semblance of multiprofessional teams can be found only in high dependency units such as accident and emergency departments, labor wards, intensive care units, and newborn special care units.

While the literature on multiprofessional collaboration in health care has steadily increased in North America and Europe, and multiprofessional collaboration has been promoted by the World Health Organization, ${ }^{13-17}$ little is known about collaborative models of health care in Africa where team working is necessary, among other benefits, to address perennial challenges such as staff shortages and interprofessional conflicts in the health sector. We found no studies that addressed team working in obstetrics and gynecology practice in South East Nigeria. The aims of this study were to describe the knowledge of interdisciplinary team working among obstetricians and gynecologists in two teaching hospitals in South East Nigeria and to determine their attitude toward development of an interdisciplinary collaborative approach to patient care in these institutions.

\section{Materials and methods}

South East Nigeria is made up of five states and has a combined population of approximately 20 million according to the 2006 Nigeria national census. ${ }^{18}$ The area is served by ten university teaching hospitals. This study took place at two of these centers in Enugu and Ebonyi states, namely, the University of Nigeria Teaching Hospital Enugu and the Federal Teaching Hospital Abakaliki, in Ebonyi State. The study population included obstetrics and gynecology consultants and resident doctors. Both centers had a total of approximately 160 doctors working in the obstetrics and gynecology departments. The study covered the period from December 1, 2013 to January 30, 2014. Ethical clearance for the study was obtained from the research ethics committees of the two study centers.

This was a questionnaire-based cross-sectional study. A convenient sample of two hospitals was selected from the ten teaching hospitals in the South East geopolitical zone of Nigeria. Doctors were approached in their outpatient clinics and informed about the study and their consent sought. Those who agreed to participate in the study were given the questionnaire (see Supplementary materials section) and asked to bring the completed questionnaire to their next clinic for collection. In all, 140 doctors working in the obstetrics and gynecology departments of both hospitals were given the questionnaire.

A 25-item, self-administered, anonymized, semistructured questionnaire developed for the study was used for data collection. The questionnaire was pretested in a group of 20 resident doctors in a sister department (pediatrics) at the University of Nigeria Teaching Hospital, Enugu. The questionnaire was in four parts: the first part was concerned with sociodemographic data; the second explored current interprofessional relationships among health workers; the third explored the respondents' awareness and knowledge of multiprofessional and interdisciplinary team working; and the fourth focused on their perceptions of and attitude toward interprofessional team working.

\section{Statistical analysis}

The statistical analysis was done using Statistical Package for the Social Sciences version 17.0 software for Windows (SPSS Inc., Chicago, IL, USA) using descriptive and inferential statistics. The main outcome measures were the proportion of respondents who had good knowledge of interdisciplinary team working and the proportion that had a good attitude toward interdisciplinary team working. Frequencies of different responses were expressed as percentages. Tests of association were done using the Pearson's chi-square test. A $P$-value of $\leq 0.05$ was considered to be statistically significant.

\section{Results}

\section{Sociodemographic characteristics}

A total of 140 questionnaires were distributed, of which 116 were returned, giving a response rate of $82.9 \%$. The mean age of the respondents was $31.9 \pm 7.0$ (range 22-51) years. Table 1 shows the sociodemographic characteristics of the respondents. 
Table I Sociodemographic characteristics of respondents

\begin{tabular}{|c|c|c|}
\hline Characteristic & Frequency $(n=|| 6)$ & Percentage \\
\hline \multicolumn{3}{|l|}{ Sex } \\
\hline Male & 110 & 94.8 \\
\hline Female & 6 & 5.2 \\
\hline \multicolumn{3}{|l|}{ Rank } \\
\hline Consultant & 24 & 19.8 \\
\hline Senior registrar & 31 & 19.8 \\
\hline Registrar & 33 & 26.4 \\
\hline Senior house officer & 18 & 34.0 \\
\hline \multicolumn{3}{|l|}{ Age group, years } \\
\hline $20-30$ & 35 & 30.2 \\
\hline $31-40$ & 47 & 40.5 \\
\hline $4 I-50$ & 33 & 28.4 \\
\hline $51-60$ & I & 0.9 \\
\hline \multicolumn{3}{|l|}{ Study site } \\
\hline UNTH & 59 & 50.8 \\
\hline FETHA & 57 & 49.2 \\
\hline \multicolumn{3}{|c|}{ Country of basic medical training } \\
\hline Nigeria & 112 & 95.6 \\
\hline UK & 2 & 1.7 \\
\hline Germany & $\mathrm{I}$ & 0.9 \\
\hline Romania & 1 & 0.9 \\
\hline
\end{tabular}

Abbreviations: UNTH, University of Nigeria Teaching Hospital; FETHA, Federal Teaching Hospital, Abakaliki.

\section{Current interprofessional relationships among health workers}

Approximately $74 \%$ of respondents were of the opinion that existing arrangements that emphasized strict professional boundaries in the formation and functioning of clinical service units in the different health professions inadvertently promoted professional segregation and rivalry. Approximately $78 \%$ (91/116) believed that interprofessional conflicts/ rivalry hinders delivery of medical care in the study centers; this opinion was expressed by $66 \%$ of consultants, $83 \%$ of senior registrars, $79 \%$ of registrars, and $76 \%$ of senior house officers. Approximately 55.2\% (64/116) of respondents had observed interprofessional conflicts in their work places. The commonest sources of conflict were assertion of professional boundaries $(48.3 \%, 56 / 116)$, superiority $(36.2 \%, 42 / 116)$, accusation of incompetence $(30.2 \%, 35 / 116)$, and accusation of irresponsibility $(18.9 \%, 22 / 116)$. The most common interprofessional conflict/rivalry identified was between doctors and other health workers.

\section{Awareness and knowledge of interdisciplinary team working}

Table 2 summarizes the responses of participants to questions on knowledge of and attitude to interprofessional team working. Approximately $74.1 \%$ (86/116) of respondents stated that they were aware of the concept of interdisciplinary
Table 2 Responses to questions about knowledge and attitude to team working

\begin{tabular}{|c|c|c|}
\hline Question & Responses (n) & Percentage \\
\hline \multicolumn{3}{|c|}{ Are you aware of the term } \\
\hline \multicolumn{3}{|c|}{ "interdisciplinary team working"? } \\
\hline \multicolumn{3}{|l|}{$(n=116)$} \\
\hline Yes & 86 & 74.1 \\
\hline No & 30 & 35.9 \\
\hline \multicolumn{3}{|c|}{ Identify any of five key components ${ }^{4-7}$} \\
\hline \multicolumn{3}{|c|}{ of interdisciplinary team working } \\
\hline \multicolumn{3}{|l|}{$(n=86)$} \\
\hline 5 correct responses & 13 & 15.1 \\
\hline 4 correct responses & 25 & 29.0 \\
\hline 3 correct responses & 20 & 23.3 \\
\hline 2 correct responses & 20 & 23.3 \\
\hline I correct response & 8 & 9.3 \\
\hline \multicolumn{3}{|c|}{ Would you accept to work in a } \\
\hline \multicolumn{3}{|c|}{ team where nurses and other health } \\
\hline \multicolumn{3}{|c|}{ professionals share responsibilities for } \\
\hline \multicolumn{3}{|c|}{ patient care with doctors? $(\mathrm{n}=86)$} \\
\hline Very readily accept & 13 & 15.1 \\
\hline Readily accept & 31 & 36.0 \\
\hline Accept & 28 & 32.6 \\
\hline Barely accept & 4 & 4.7 \\
\hline No & 10 & 11.6 \\
\hline \multicolumn{3}{|c|}{ Are you happy to consult with and/ } \\
\hline \multicolumn{3}{|c|}{ or communicate your thoughts about } \\
\hline \multicolumn{3}{|c|}{ patient care to nurses or other health } \\
\hline \multicolumn{3}{|c|}{ workers in your team and have them } \\
\hline \multicolumn{3}{|c|}{ offer their opinions to guide your } \\
\hline \multicolumn{3}{|c|}{ decisions about patient care? $(\mathrm{n}=86)$} \\
\hline Very happy & 21 & 24.4 \\
\hline Happy & 52 & 60.5 \\
\hline Barely happy & 3 & 3.5 \\
\hline No & 10 & 11.6 \\
\hline \multirow{3}{*}{\multicolumn{3}{|c|}{$\begin{array}{l}\text { Will you support the establishment } \\
\text { and implementation of transdisciplinary } \\
\text { teams in your department? }(n=86)\end{array}$}} \\
\hline & & \\
\hline & & \\
\hline Yes & 66 & 76.7 \\
\hline No & 20 & 23.3 \\
\hline
\end{tabular}

team working, with $15 \%$ of these having very good knowledge, $35 \%$ having good knowledge, and $29 \%$ having poor knowledge. Approximately 37\% (32/86) of respondents who were aware of team working reported received formal teaching/training on multiprofessional team working in the course of their professional development.

\section{Attitude to interprofessional team working}

Approximately $71 \%(61 / 86)$ of the respondents believed that medical care would be best delivered by interdisciplinary teams, and $74.1 \%(64 / 86)$ felt that interprofessional team working was feasible in Nigeria. Seventy-three percent $(63 / 86)$ felt that interdisciplinary team working 
would be necessary for the development and functioning of subspecialty units in obstetrics and gynecology at Nigerian hospitals. Approximately $77.6 \%$ (67/86) of respondents who were aware of team working believed that interdisciplinary teams would be useful in obstetrics and gynecology practice in Nigeria, with $89 \%$ of these $(60 / 67)$ rating its prospects as very useful.

\section{Discussion}

This was an initial prevalence study to evaluate the feasibility of implementing interdisciplinary team working in Nigerian hospitals. We chose to emphasize interdisciplinary team working because other types of multiprofessional team working may not suitable for our environment given our level of socioeconomic development. Multidisciplinary team working does not allow sufficient collaboration to tap the expertise of different professions, while the blurring of professional boundaries in transdisciplinary team working may require higher than existing levels of professional discipline and control in our society. We also chose to evaluate the knowledge and attitude of physicians first because doctors drive most clinical activities in our hospitals and their attitude to interdisciplinary collaboration could be key to operationalizing any policy to introduce interdisciplinary team working in government-owned health institutions in Nigeria. ${ }^{19}$

Our results show a high level of awareness of interprofessional team working among respondents. However, this did not translate into a high level of knowledge of the meaning of the concept of interprofessional team working. The results suggest that awareness was not based on a deep understanding of the meaning and content of interprofessional team working. This may not be surprising considering that a much smaller proportion of respondents had been exposed to formal teaching or training on interprofessional team working. Therefore, this study suggests that there might be a need for theoretical training of health workers on interdisciplinary team working in the study centers. Anecdotal evidence suggests that team working is not taught in medical or nursing schools in Nigeria, unlike in Europe, the UK, and the USA. While changes in the curricula of Nigerian medical schools might need to include team working, short-term measures, such as workshops and update courses, could be organized for health workers to include topics on interprofessional team working.

Meanwhile, a very high proportion of respondents agreed that interprofessional rivalry was an important feature of patient care in the two departments studied. This may mirror the situation of medical practice in the entire country, given a previous study showing that the recent industrial disputes in the Nigeria health sector had been instigated by struggles between doctors and other health professionals for leadership of the health team. ${ }^{20} \mathrm{~A}$ high proportion of respondents in this study expressed the opinion that the current method of organizing clinical units in the different professions promoted unnecessary professional segregation and fanned rivalry. Such rivalries should be a matter for serious concern for two reasons. First, although they may still allow work in hospitals to proceed in a coordinated way, fractious relationships arising from them may delay the processes of care. ${ }^{21}$ Secondly, they could engender an unfriendly working environment, which could impair the efficiency of individual health workers as well as that of the system itself. ${ }^{21}$ Our results suggest that respondents acknowledged the need to begin to think about promoting professional collaboration in order to improve patient care in our hospitals.

Our results also show that there was a significant desire for team working by doctors in the obstetrics and gynecology departments of the study centers. This was associated with a strongly positive attitude toward interdisciplinary team working. This finding suggests that the attitudes of doctors may not be an impediment to the establishment and implementation of collaborative interprofessional team working in this area. This finding is important, given the dominant position of doctors in public hospital services.

Although this study involved only one department and a relatively small proportion of all health workers, our results suggest the need to begin to look into ways of entrenching collaborative care in our hospitals. More research will definitely be needed to determine the views of health workers across different professions; however, we do not expect the opinions of doctors in other departments in the study centers to be markedly different from those of their colleagues in the obstetrics and gynecology department. Curriculum developers should explore ways of increasing interprofessional education among the different health professions in Nigeria in order to expose potential entrants into the professions to collaborative relationships early in their careers. ${ }^{22}$ The usefulness of interprofessional education in promoting and facilitating interdisciplinary team working has been extensively explored in the literature. ${ }^{23-26}$

The limitations of this study include the use of a single profession and one department in each hospital, which limits the external validity of our results. Although qualitative studies should have been able to explore the opinions of respondents in greater detail, use of anonymized self- administered questionnaires enabled the respondents to express their opinions freely without bias. No formal psychometric 
analysis of the questionnaire was undertaken, but the ability of the questionnaire to elicit correct responses from respondents was ensured by pretesting and modification of the final version based on the results of the pretest.

\section{Conclusion}

We conclude that there was a fair knowledge of the concept and a very positive attitude toward interprofessional team working among obstetricians and gynecologists in the study centers, suggesting that the attitude of physicians may not be an impediment to implementation of a collaborative interdisciplinary approach to clinical care in the study centers.

\section{Disclosure}

The authors report no conflicts of interest in this work.

\section{References}

1. Oandasan I, Ross Baker G, Barker K, et al. Team working in health care: promoting effective team work in health care in Canada-policy synthesis and recommendations. Ottawa, ON, USA: Canada Heath Services Research Foundation; 2006. Available from: http://www.cfhi-fcass.ca/ Migrated/PDF/teamwork-synthesis-report_e.pdf. Accessed April 28, 2015 .

2. Gaboury I, Lapierre LM, Boon H, Moher D. Interprofessional collaboration within integrative health care clinics through the lens of the relationshipcentred model of care. J Interprof Care. 2011;25:124-130.

3. D'Amour D, Ferrada-Videla M, San Martin Rodriguez L, Beaulieu M. The conceptual basis for interprofessional collaboration: core concepts and theoretical frameworks. J Interprof Care. 2005;Suppl 1:116-131.

4. Choi BC, Pak AW. Multidisciplinarity, interdisciplinarity and transdisciplinarity in health research, services, education and policy: definitions, objectives and evidence of effectiveness. Clin Invest Med. 2006;29: 351-364.

5. Thylefors I, Persson O, Hellstrom D. Team types, perceived efficiency and team climate in Swedish cross professional team work. J Interprof Care. 2005;19:102-114.

6. Paul S, Peterson CQ. Interprofessional collaboration: issues for practice and research. Occup Theory Health Care. 2001;15:1-12.

7. Batorowicz B, Shepherd TA. Team working in AAC: examining clinical perceptions. Augment Altern Commun. 2011;27:16-25.

8. Drotar D. Reflections on interdisciplinary collaboration in the new millennium; perspectives and challenges. Dev Behav Ped. 2002;23: $175-180$.
9. Leggat SG. Effective health care teams require effective team members: defining team competencies. BMC Health Serv Res. 2007;7:17-26.

10. San Martin-Rodriguez L, Beaulieu M, D’Amour D, Ferrada-Videla M. The determinants of successful collaboration: a review of theoretical and empirical studies. J Interprof Care. 2005;Suppl 1:132-147.

11. Mickan SM. Evaluating the effectiveness of health care teams. Aust Health Rev. 2005;29:211-217.

12. ManserT. Teamwork and patient safety in dynamic domains of healthcare. A review of the literature. Acta Anesth Scand. 2009;53:143-151.

13. World Health Organization. Framework for action on interprofessional education and collaborative practice. Geneva, Switzerland: World Health Organization; 2010.

14. Molyneux J. Interprofessional teamworking: what makes teams work well? J Interprof Care. 2001;15:30-35.

15. Suter E, Arndt J, Arthur N, Parboosingh J, Taylor E, Eutschlander S. Role understanding and effective communication as core competencies for collaborative practice. J Interprof Care. 2009;23:41-51.

16. Baxter SK, Brumfitt SM. Professional differences in interprofessional working. J Interprof Care. 2008;22:239-251.

17. Bleakley A, Boyden J, Hobbs A, Walsh L, Allard J. Improving teamwork climate in operating theatres: the shift from multiprofessionalism to interprofessionalism. J Interprof Care. 2006;20:461-470.

18. National Population Commission of Nigeria. Population and Housing Census, 2006. Available from: http://catalog.ihsn.org/index.php/ catalog/3340. Accessed April 28, 2015.

19. Adindu A, Asuquo A. Training human resource for 21 st century Nigerian health sector. Global Journal of Human Resource Management. 2013;1:1-11.

20. Erhabor OE, Adias TC. Harmony in health sector: a requirement for effective healthcare delivery in Nigeria. Asian Pac J Trop Biomed. 2014;4:925-929.

21. Barr H. Commentary: the WHO framework for action. J Interprof Care. 2010;24:475-478.

22. Lorenz W. Europe, the professions and interprofessional education: an exploration in inter-culture relativity. J Interprof Care. 2009;23: 432-441.

23. Reeves S, Zwarenstein M, Goldman J, et al. Interprofessional education: effects on professional practice and health care outcomes. Cochrane Database Syst Rev. 2008;1: CD002213.

24. Freeth D, Hammick M, Reeves S, Koppel I, Barr H. Effective Interprofessional Education: Development, Delivery and Evaluation. London, UK: Blackwell; 2005.

25. Hammick M, Freeth D, Koppel I, Reeves S, Barr H. A best evidence systematic review of interprofessional education: BEME Guide No 9. Med Teach. 2007;29:735-751.

26. Barr H, Koppel I, Reeves S, Hammick M, Freeth D. Effective Interprofessional Education: Assumption, Argument and Evidence. London, UK: Blackwell; 2005. 


\section{Supplementary materials Questionnaire}

Section 1 Sociodemographic characteristics

Fill or tick as appropriate

a. Age (years).

b. Sex

c. Religion (denomination).

d. Professional rank.

e. Institution/health facility where you work: Tick as appropriate

- Federal Teaching hospital Abakaliki

- University of Nigeria Teaching hospital

f. Which country did you have your basic medical degree? State as appropriate

Nigeria

UK

USA

Germany

Others: state as appropriate.

Section 2 Current interprofessional relationship among health workers

Tick yes or no, or fill as appropriate

a. Do you think that current ways of organizing professional groups in patient care in your hospital promotes interprofessional conflicts? Tick yes or no

- Yes

- No

b. Are there any interprofessional conflicts that you have observed among your work colleagues and other professionals in your department?

- Yes

- No

c. If you ticked yes to the question above, state the type of conflicts that you have observed

d. Which of these have you experienced in the course of your work in your center? Tick as appropriate

- Being told that some procedures are meant for other doctors or other professionals

- Being told by colleagues or other professionals that you should mind your own work

- Working in an arrangement where professional boundaries are emphasized

- Being reported to a higher officer for interfering with other peoples professional responsibilities

e. What do you consider the impediments to team working in obstetrics and gynecology care in Nigerian hospitals?

Section 3 Awareness and knowledge of interdisciplinary team working

a. Are you aware of the term interdisciplinary team working? Tick yes or no

- Yes

- No

b. Have you been exposed to any form of training on team working? Tick yes or no

- Yes

- No 
c. Identify the key components on interprofessional team working: tick five correct responses

- Common decision-making process

- Decisions made by doctors as leaders of the health team

- Common goal

- Goals are based on individual professions

- Regular meetings

- Meetings are held only when the leader chooses

- Contribution of expertise in collective patient care within each professional area

- Professional expertise can be contributed in any area a member chooses

- Common approach

- Each profession chooses its own approach to patient care

Section 4 Attitude to interdisciplinary team working

a. Do you consider interdisciplinary team working as a useful approach to effective and sustainable high quality obstetrics and gynecology care in Nigeria? Tick yes or no

- Yes

- No

b. How would you rate the usefulness of interdisciplinary team working in the delivery of obstetrics and gynecology care? Tick only one as appropriate

- Very useful

- Moderately useful

- Useful

- Not useful

c. Will you accept to work in a team where nurses and other health professionals share responsibilities for patient care with doctors? Tick as appropriate

- Very readily accept

- Readily accept

- Accept

- Barely accept

- No

d. Do you think that interprofessional team working is necessary for the establishment and maintenance of subspecialty units in obstetrics and gynecology care in Nigeria? Tick yes or no

- Yes

- No

e. Do you think that it is feasible to form interprofessional teams in obstetrics and gynecology departments in Nigerian hospitals? Tick yes or no

- Yes

- No

f. Are you happy to consult with and/or communicate your thoughts about patient care to nurses or other health workers in your team and have them offer their opinions to guide your decisions about patient care? Tick as appropriate

- Very happy

- Happy

- Barely happy

- No 


\section{Publish your work in this journal}

The Journal of Multidisciplinary Healthcare is an international, peerreviewed open-access journal that aims to represent and publish research in healthcare areas delivered by practitioners of different disciplines. This includes studies and reviews conducted by multidisciplinary teams as well as research which evaluates the results or conduct of such teams or

healthcare processes in general. The journal covers a wide range of areas and welcomes submissions from practitioners at all levels, from all over the world. The manuscript management system is completely online and includes a very quick and fair peer-review system. Visit http://www.dovepress.com/testimonials.php to read real quotes from published authors.

Submit your manuscript here: http://www.dovepress.com/journal-of-multidisciplinary-healthcare-journal 